\section{Combining research with training: results of research on the Internet training needs of community library staff using a one-day course}

\section{Margaret Kendall}

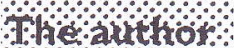 \\ $\therefore$ \\ Margaret Kendall is a Senior Lecturer in the \\ Department of Information and Communications, \\ Manchester Metropolitan University. Prior to \\ becoming a lecturer, she held a variety of professional \\ posts in public libraries in Oldham and Manchester, \\ including the post of Team Leader: West Area for \\ Manchester Cultural Services Department. E-mail: \\ m.a.kendall@mmu.ac.uk
}

\section{Mistioto}

This article reports on a research project on the Internet training needs of public library staff in the Greater Manchester region. The methods used were built around six repeat sessions of a one-day course. The course was a positive experience for participants and provided quantitative and qualitative data. The findings show that the research methods were highly effective, and that an interest in the facilities of the Internet quickly develops if staff are guided to material directly relevant to their work. With the forth-coming investment in ICT training, the methods could be replicated to assess their impact.

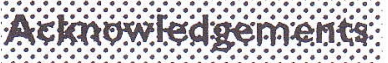

The author would like to thank all the participants in the training courses for their contributions. Thanks are also given to Jenny Craven and Steve Bunyan, for support in delivering the courses, Richard Eskins for technical support, and Jonathan Willson, Dick Hartley and Maggie Walker for advice and support throughout the research project.

\section{Introduction}

Training for public library staff has been recognised as an essential first step towards realising the vision of New Library: the People's Network, (Library and Information Commission, 1997). The Task Group - established to advise the New Opportunities Fund on the best way of using the $£ 20 \mathrm{M}$ allocated by the Government for training - identified a range of skills in Information and Communication Technology in order for staff to

"feel comfortable both when using IT themselves and when helping others to make constructive use of IT." (LIC, 1998, Part 2)

The Task group report also identifies university departments of Library and Information studies as potential contributors to the provision of basic and advanced training.

The Making Connections research project, the subject of this report, began in early 1998 and aimed to identify:

- The Internet training and development needs of community library staff in the Greater Manchester region

- The potential short and long-term roles of Manchester Metropolitan University's Department of Information and Communications in meeting those needs.

From March to November 1998, repeat sessions of a one-day course for staff with responsibility for community or branch libraries were used as a means of collecting data through a variety of quantitative and qualitative methods. This approach enabled a deeper insight to be gained of the levels of support and training needed, and the appropriateness of the delivery methods. This article concentrates on the research methods used, discusses their effectiveness and the key findings. Further details of the course content and how it was received are given in Kendall (1999). 


\section{The one-day course}

Fundamental to the recommendations (LIC, 1997), is the concept of the local library as a place which people of all ages will be able to visit to develop skills and to access information and resources through new technology. Unlike staff in the larger subject departments of central libraries, staff with responsibility for community or branch libraries perform very different roles and may have had little previous opportunity to use electronic information resources whether online or on CD-ROM. Asking people about their training needs when they were unaware what is available was thought likely to be of limited value, so a one-day course demonstrating the potential of future networked public library services was chosen as a means of gathering responses from participants.

The overall aim of the one-day course was to provide focused training relevant to the participants' responsibilities. The objectives were:

- To raise participants' awareness and understanding of the future role of public libraries in increasing public use of information and communication technologies

- To demystify the technology and help participants to develop confidence, enthusiasm and practical skills in using World Wide Web resources and tools.

- To raise the awareness of participants of existing examples of co-operation between librarians and resources created by or for librarians

A variety of delivery methods were used, supported by printed handouts as appropriate. Using a large-screen Elmo Visual Presenter system, information-giving presentations included Powerpoint slides, online demonstrations of the Netscape Navigator browser and World Wide Web resources, a short animated sequence explaining Web technology (Blomeley, Morris and Stone, 1998) and a video (Birmingham Library Services, 1997).

The major part of the day however, was set aside for individual hands-on practice on twenty networked Pentium personal computers in one of the Department's laboratories. An online tutorial, A Site-Seeing Tour, featured websites for children, fiction and community information. These drew from the author's experience of integrating ICT into the teaching of relevant electives on the $\mathrm{BA} / \mathrm{BSc}$ Information and Library Management course (Kendall, 1997, 1998). Practical exercises in searching, and in exploring resources such as co-operative enquiry services, were also used.

In total, 99 participants attended six one-day courses; the first of these was a pilot course, and one was a customised version for staff from an individual authority. Decisions about who should attend were left to each authority. Approximately $76 \%$ were from branch or community libraries, the remainder were from large town or central libraries. 63 were professional staff at varying levels of seniority, 36 were paraprofessionals - of whom 25 were senior library assistants and 11 were library assistants.

\section{Research Methods}

\section{Questionnaires}

Invitations to send one participant to the pilot course in March 1998 were posted to each of the 10 Greater Manchester public library authorities (Bolton, Bury, Manchester, Oldham, Rochdale, Salford, Stockport, Tameside, Trafford and Wigan) and the neighbouring authorities of Cheshire, Lancashire and Kirklees. Charging a nominal fee for the pilot course with an explanation that it formed part of a research project ensured that each library authority was represented. It also helped to create good will in the full return of the pre-attendance questionnaire. As well as using this to identify existing skills as a traditional method of training needs analysis (Williamson, 1993), the questionnaire enabled a "snapshot" picture of provision of access to the Internet for the general public in the Greater Manchester area to be gained.

The distribution of one postal questionnaire to each authority asking about Internet access might have achieved a similarly full response, but sending further postal questionnaires regularly 
over the following months would have been likely to have had reduced success and risked irritating busy practitioners. By using the subsequent training courses as a means of further data collection (both through the pre-course questionnaire and through focus group discussions), it was possible to gain an awareness of changes as they happened and their impact on the library authorities concerned. The preattendance questionnaire was modified slightly after the pilot course, to gather more information about individual access to the Internet, including whether or not participants had access from home. Any participant who had not returned the questionnaire in advance was asked to complete one upon registration.

An anonymous questionnaire at the end of the course was used to gather more detailed responses to the different elements of the course than would normally be expected on a one-day course, with the aim of being more than a "happiness sheet" (Whetherley, 1994, p.25). In addition to asking for evaluation of the usefulness and appropriateness of the training methods according to a five-point scale, participants were encouraged to make comments after each question. Time was allowed for completion of the questionnaire during the refreshment break before the final discussion session, in order to encourage a full response rate. This was a successful strategy, since only one respondent (who went outside the building to smoke) did not comply! However, not everyone answered all the questions, and some . questions were added after the pilot course.

The first session of the day was a short presentation to set the course in context. This used quotations from reports from 1997 onwards (Department of National Heritage, 1997) identifying the public library as a key location for public access to electronic information resources. This provided the opportunity to investigate levels of awareness of the reasons for the changes taking place. A handout with the quotations was included in the course pack and participants were asked to refer to this as a reminder, when completing the end of course questionnaire.
A further questionnaire was sent to participants from the first four courses to gather their views as to the usefulness of the course since attendance and to identify additional training needs. This questionnaire also asked for details of any changes in the provision of access to the Internet in the library at which the participant was based. 36 out of a possible 63 responses were received, a $57 \%$ response rate which compares favourably with many postal questionnaires. This may have resulted from the positive experience reported by participants, and from the fact that they had met the trainer/researcher.

\section{Individual responses and focus groups}

The courses provided a unique opportunity to collect the views and responses of participants to World Wide Web resources, their potential uses in public library services and the changes likely to be required in the workplace.

In order to capture individual responses anonymously, participants were given a pad of adhesive "post-it" notes at the beginning of the day, with an invitation to record their "Thoughts and ideas" (for example, for introducing the World Wide Web to users) as they happened. It was also thought important to allow participants to record negative responses, called "Issues and fears" (for example, changes in the workplace, training needs, theft) throughout the day. Towards the end of the morning and afternoon sessions, people were invited to come up individually to stick their post-it notes on appropriately headed flipcharts, and were given a short amount of time to read each other's responses, prior to discussion sessions. One aim of this as a method of data collection was to complement the end of the course questionnaire in evaluating the online tutorial as a means of raising enthusiasm and interest. Also, as the courses were designed for participants with little or no experience in using the World Wide Web, it was felt that some participants might be reluctant to participate in discussions, for fear of revealing their lack of knowledge. However carefully facilitated, some more vocal participants might deter contributions from the more reticent. 
Whilst there was limited time available for focus groups, two half-hour discussion sessions were scheduled for the end of the morning and afternoon sessions. Research Assistants made notes on the discussion, and also noted relevant comments and conversations throughout the day.

The first focus group was loosely structured, with the researcher asking someone to start off with a response to the question "Which of the web sites in the tutorial would you most want to show to a user in your library and why?", moving onto someone else and another web site after discussion. The second focus group involved more intervention from the researcher, with questions presented using overhead transparencies to control the discussion. On the pilot course, a series of questions were asked about the options for further training provision from the Department of Information and Communications. On the subsequent courses, participants were asked to discuss ways in which public libraries could interest their users in the World Wide Web, and the changes which would need to take place in order for this to happen.

\section{Key findings}

Internet Access in the region The pre-course questionnaire revealed that, at the time of the pilot course, $8(62 \%)$ of the 13 library authorities provided access to the Internet for the general public, with some services having been established very recently. However, in some. cases, access for the public was limited to only one library per authority, and only two authorities had more than 5 libraries connected. This reflects the national situation. Batt (1998) found that $77 \%$ of UK library authorities had Internet access at the time of his survey, but only 215 of 4095 service points (5\%) provided public access.

By July two further authorities had introduced public access bringing the total to $11(85 \%)$. In one authority pressure from the public, who were aware that Internet services were provided by a neighbouring authority, had led to the introduction of the service before staff felt prepared. Several authorities applied "self-help" policies, with explanations given to the public that staff could do no more than help people in the practicalities of logging on and off; one had a coin-operated system. As the course enabled people to gain greater awareness of the ways in which they could use the Internet to enhance and develop existing services, participants became more critical of these policies in the focus group discussions. The lack of staff access emerged as a consistent theme, as in only three library authorities did participants have staff only access to the Internet in the library at which they were based. A different approach in one authority was reported in the post-attendance questionnaire, with two staff access machines having been introduced at the participant's workplace since attendance on the course, with access for the public to follow.

Course evaluation The end of course questionnaire indicated high levels of satisfaction with the courses overall, with 79 (82\%) giving the highest ranking of Very useful and the remaining $17(18 \%)$ giving the second ranking of Useful.

Table 1 shows some of the questionnaire responses to the different elements of the course.

Table 1 Satisfaction with course

\begin{tabular}{|c|c|c|c|c|c|c|}
\hline & Very useful & Useful & \begin{tabular}{|l|} 
Neither \\
useful nor \\
not useful
\end{tabular} & $\begin{array}{l}\text { Not very } \\
\text { useful }\end{array}$ & Not useful & $\begin{array}{l}\text { Total no. of } \\
\text { respondents }\end{array}$ \\
\hline $\begin{array}{l}\text { Overview of } \\
\text { reports }\end{array}$ & $\begin{array}{l}29 \\
(31 \%) \\
\end{array}$ & $\begin{array}{l}58 \\
(61 \%) \\
\end{array}$ & \begin{tabular}{|l}
6 \\
$(6 \%)$ \\
\end{tabular} & $\begin{array}{l}2 \\
(2 \%)\end{array}$ & & 95 \\
\hline $\begin{array}{l}\text { Netscape } \\
\text { Navigator } \\
\text { handout }\end{array}$ & $\begin{array}{l}42 \\
(46 \%)\end{array}$ & $\begin{array}{l}47 \\
(51 \%)\end{array}$ & $\begin{array}{l}3 \\
(3 \%)\end{array}$ & & & 92 \\
\hline $\begin{array}{l}\text { Online } \\
\text { tutorial }\end{array}$ & $\begin{array}{l}58 \\
(74 \%) \\
\end{array}$ & $\begin{array}{l}20 \\
(26 \%) \\
\end{array}$ & & & & 78 \\
\hline Video & $\begin{array}{l}11 \\
(15 \%)\end{array}$ & $\begin{array}{l}42 \\
(57 \%)\end{array}$ & $\begin{array}{l}21 \\
(28 \%)\end{array}$ & & & 75 \\
\hline
\end{tabular}


Some of the comments indicated that the aim of creating interest through course material directly related to the work carried out by the target audience had been achieved:

"This is proof that this is a resource which should be available in every library and would be a boon to our Information services"

The post-attendance questionnaire showed continued satisfaction with the course, with many comments relating to the value of being introduced to sites and resources relevant to fiction, community information and for children
Levels of awareness A key factor in the success of the future networked public library will be a shared understanding of the need for change. The results of the question about course participants' awareness of recent reports showed that no assumptions can be made about staff knowledge of current developments, both in their own and related fields.

Table 2 Before today, which of the following reports had you?

\begin{tabular}{|l|l|l|l|l|}
\hline & $\begin{array}{l}\text { Heard of } \\
\text { but not read? }\end{array}$ & Read? & Not heard of? & $\begin{array}{l}\text { Total no of } \\
\text { responses }\end{array}$ \\
\hline $\begin{array}{l}\text { DNH: Reading the future } \\
\text { Lottery }\end{array}$ & $35(36 \%)$ & $29(30 \%)$ & $34(35 \%)$ & 98 \\
\hline $\begin{array}{l}\text { Audit Commission: Due for } \\
\text { Renewal }\end{array}$ & $55(56 \%)$ & $10(10 \%)$ & $33(34 \%)$ & 98 \\
\hline $\begin{array}{l}\text { LC: New Library: the } \\
\text { People's Network }\end{array}$ & $34(35 \%)$ & $32(33 \%)$ & $32(33 \%)$ & 98 \\
\hline $\begin{array}{l}\text { DfEE: Connecting the } \\
\text { Learning Society }\end{array}$ & $37(38 \%)$ & $10(10 \%)$ & $51(52 \%)$ & 98 \\
\hline $\begin{array}{l}\text { DfEE: The Learning Age: a } \\
\text { renaissance for new Britain }\end{array}$ & $24(30 \%)$ & $4(5 \%)$ & $53(65 \%)$ & 81 \\
\hline $\begin{array}{l}\text { DCMS: New Library: the } \\
\text { People's Network: the } \\
\text { Government's response }\end{array}$ & $32(40 \%)$ & $25(31 \%)$ & $24(29 \%)$ & 81 \\
\hline
\end{tabular}

The results indicate that, in addition to ICT skillsbased training, there is a need for explanation as to why these skills are becoming essential for the public library service of the future, particularly for it to continue to fulfil its complementary role to formal education.

Responses to this question may have benefited from the participants' positive feelings at the end of a training course, resulting in a fuller, more honest response than might have been the case had the question been posed in a separate survey, e.g. a postal questionnaire. An atmosphere of trust had been created, which made assurances of individual anonymity more credible.

From the pre-attendance questionnaire used on 5 of the 6 courses, it was found that $32(45 \%)$ of the participants had had some prior training in using the web. A checklist of their awareness of search tools revealed that even those with the most experience were unaware of some resources which could be helpful in responding to users' enquiries. 
Table 3 Search tools: have you used?

\begin{tabular}{|l|c|c|}
\hline & $\begin{array}{c}\text { Number } \\
\text { answering } \\
\text { 'yes' }\end{array}$ & $\begin{array}{c}\text { Percentage } \\
\text { of total } \\
\text { respondents }\end{array}$ \\
\hline Yahoo? & 40 & $52 \%$ \\
\hline Lycos? & 15 & $19 \%$ \\
\hline Alta Vista? & 36 & $47 \%$ \\
\hline $\begin{array}{l}\text { A meta search engine, e.g. } \\
\text { Metacrawler? }\end{array}$ & 8 & $10 \%$ \\
\hline BUBL-Link? & 1 & $1 \%$ \\
\hline EARL-Web? & 6 & $8 \%$ \\
\hline Total no. of respondents & 77 & \\
\hline
\end{tabular}

A further opportunity to gain feedback from participants on an EARL Family History task group workshop held in the Department in May, revealed that awareness of BUBL-Link, SOSIG and the Internet Public Library was low amongst professionals with more experience of using the Web. One commented

"I already use the Internet - often searching on a daily basis, but was unaware of some of these sites which could be useful".

Thoughts \& ideas, issues and fears The extent to which the post-it notes were used varied with individuals: it seemed to appeal to some more than others. The number of responses generated indicate that it was a useful way of collecting additional data.

The majority of positive comments on the post-it notes were reactions to individual web sites, featured in the online tutorial, which had been found useful. From the Community Information section, many were delighted by the information provided on the Government Information service that could be useful for answering enquiries. Several were enthusiastic about the European Citizen First site. One said it would have given the answers for two recent enquiries which had been unable to be answered from the resources of a small branch library. The first was from a user wishing to know more about teaching in France, the second was considering a move to Ireland. The discussion sessions which followed the online tutorial were consistently lively, with participants sharing their experiences with enthusiasm. The use of the post-it notes may have been helped the discussion to be successful, by enabling participants to feel prepared for what they wanted to say by having written down their individual responses. An indication that their enthusiasm was not short-lived was given from the responses to the post-attendance questionnaire. Some commented on using the sites in subsequent work, including the preparation of a newsletter for the National Year of Reading.

There were lively focus group discussions at the end of each course. Apart from the pilot course, these involved asking participants to discuss ways in which public libraries could interest their users in the Web, and then the changes which would need to take place for this to happen. As time was limited, the use of overhead transparencies to pose the two questions was found to be effective in signalling time to move on. Other than that, care was taken by the researcher not to influence the discussion.

In response to the first question, there were many practical suggestions for ways forward. These included using the Web for homework clubs, school library services, as part of themed fiction promotions. Several participants commented on the value of meeting people from other authorities and the stimulation created by opportunities for discussion of ideas. 
Combining research with training Margaret Kendall

Responses to the second question developed some of the concerns identified on the post-it notes. Goulding (1997) maintains that one of the major benefits of focus groups

"is that participants engage with one another and, thus, articulate the issues and themes of most interest and importance to them within the subject of discussion" (p.334-335).

This was found to be the case, with participants appreciating the opportunity to compare operational issues with people from other library authorities. Each group tended to focus on one issue primarily, in addition to the need for further training. These were:

- The differences in charging policies, starting from a consensus that developments in integration of the use of the Web into existing services (e.g. useful sites for fiction readers) will be dependent on free access for the public.

- Variations in attitudes towards access for children and filtering software, following the discovery that one library authority imposed no restrictions whereas another only allowed access for people over 18 .

- Staffing issues, including concerns about unequal opportunities for the acquisition of Internet skills (e.g. by those with access at home) leading to promotion or an unfair distribution of responsibilities within a team. One participant described how she had been left to carry out all other functions within the library since her male colleague had become a "netaholic", with encouragement from managers.

- Concerns about finance, and fears that a changed focus to ICT would lead to the marginalisation of other services which the public value highly.

When the course was planned, the end-of-the-day discussion session was thought to be more for the benefit of the researcher than the participants. However, it became evident that it was a valuable part of the course in its own right. Some participants swapped contact addresses and agreed to keep in touch about developments in their authorities. Informal collaboration could
Library \& Information Research News (LIRN) Volume 23 - Number 73 - Spring 1999

lead to the co-operation which networking between public libraries will require. Further cooperation could be the means of sustaining skills achieved by formal training and encourage creativity. A considerable amount of progress has been made since the Earl Consortium began in November 1995, including the creation of new products through the voluntary efforts of public library staff.

\section{Course delivery options}

The focus group discussions on the pilot course centred on the options for further training. The group showed a strong preference for attendance on courses away from the workplace. Given the low levels of Internet access in some parts of the region, with limited opportunities for staff to use the facilities, attendance on courses provided at a central location will be appropriate for the time being. The opportunity for up to 40 people to have individual hands-on simultaneous access to the University's high speed network connection is unlikely to be matched by training resources available in each local authority for some time to come.

The participants identified more disadvantages than advantages with the conversion of the course into an open/distance learning course. Although it would be cheaper and would enable people to work in their own time, they felt that they had achieved much more in the practical sessions than they would have done on their own, because they were able to discuss sites with each other. They felt that beginners would be more likely to give up if they experienced difficulties without a tutor on hand. Computer conferencing between a tutor and course members was thought to be more appropriate for staff with more experience.

A proposal for a more advanced course, with attendance over a number of weeks, was enthusiastically received. The need to develop searching skills was highlighted as being the greatest priority. The option of providing this course via open or distance learning was thought more appropriate than a course for beginners, with the suggestion being made that it be preceded by attendance on an introductory course. 
Interestingly, the national BECTa survey carried out several months later (LIC, 1998) found that a short course with continuing online support in the workplace was one of two most popular methods of training, the other being in-house training.

\section{Conclusions}

At the time of writing, a response to the recommendations from the Training Task Group (LIC, 1998) is awaited. Whatever this is, the Making Connections research project has achieved its aims of gaining an insight into the training needs of library staff in the region, and providing the Department with information for future planning. The idea of using a training course as a means of carrying out research was effective in enabling both quantitative and qualitative data collection. The advantages of collecting data in this way were that :

- it enabled a snapshot of Internet access in the region to be gained

- high numbers of responses to questionnaires were obtained

- detailed answers to questions about awareness of recent reports were given

- individual responses to web resources and to the changes taking place were collected

- ideas for future action and issues of concern to library staff were collected

- feedback was obtained from participants on possible future courses from the Department.

When plans for the training funded by the New Opportunities Fund are put into effect, both internal and external research will be essential to monitor progress and the effectiveness of investment. However, there are limits to the extent to which staff undergoing unprecedented change will have the time or willingness to respond to numerous surveys by external researchers. The use of data collected as part of the process of providing training could be a way of assessing its value and impact on those being trained.

\section{References}

Batt, C. (1998) Information technology in public libraries 6th edition, Library Association

Birmingham Library Services (1997) Your library, your future [Video] Birmingham City Council, LBV Television productions

Blomeley, F. Morris, P and Stone, P. (1998) Cartoon Images for Network Education [Online] URL http://www.kcl.ac.uk/projects/cine/movies/

Department of National Heritage (1997) Reading the future HMSO

Goulding, A. (1 997) Joking, being aggressive and shutting people up: the use of focus groups in LIS research Education for Information I5(4) PP.33 |-341

Kendall, M. (1997) Web for the Community Library Association Record 99 (4) pp.2। 2-214

Kendall, M. (1998) Look for a good read online Library Association Record 100 (I) PP. 30-33

Kendall, M. (1999) Making connections Library

Association Record 101 (2) pp.98-101

Library and Information Commission (1997) New Library: the People's Network [Online] URL http://www.ukoln.ac.uk/services/lic/newlibrary/full.html

Library and Information Commission (1998) Building the New Library Network [Online] URL http://www.lic.gov.uk/publications/building.html

Whetherley, J. (1994) Management of training and staff development Library Association

Williamson, M. (1993) Training needs analysis Library Association 